AIR COMMAND AND STAFF COLLEGE AIR UNIVERSITY

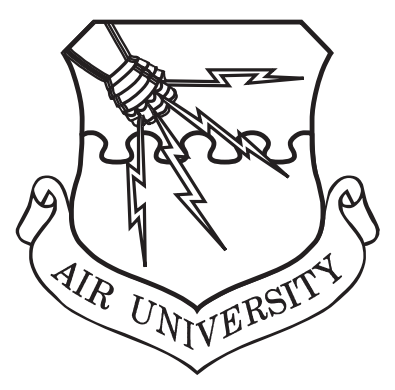

\title{
The Operational and Tactical Nexus \\ Small Steps toward Seamless Effects-Based Operations
}

\author{
M. Shane Riza \\ Major, USAF \\ Air Command and Staff College \\ Wright Flyer Paper No. 22 \\ Air University Press \\ Maxwell Air Force Base, Alabama
}

February 2006 


\section{Report Documentation Page}

Form Approved

OMB No. 0704-0188

Public reporting burden for the collection of information is estimated to average 1 hour per response, including the time for reviewing instructions, searching existing data sources, gathering and maintaining the data needed, and completing and reviewing the collection of information. Send comments regarding this burden estimate or any other aspect of this collection of information,

including suggestions for reducing this burden, to Washington Headquarters Services, Directorate for Information Operations and Reports, 1215 Jefferson Davis Highway, Suite 1204, Arlington

VA 22202-4302. Respondents should be aware that notwithstanding any other provision of law, no person shall be subject to a penalty for failing to comply with a collection of information if it

does not display a currently valid OMB control number.

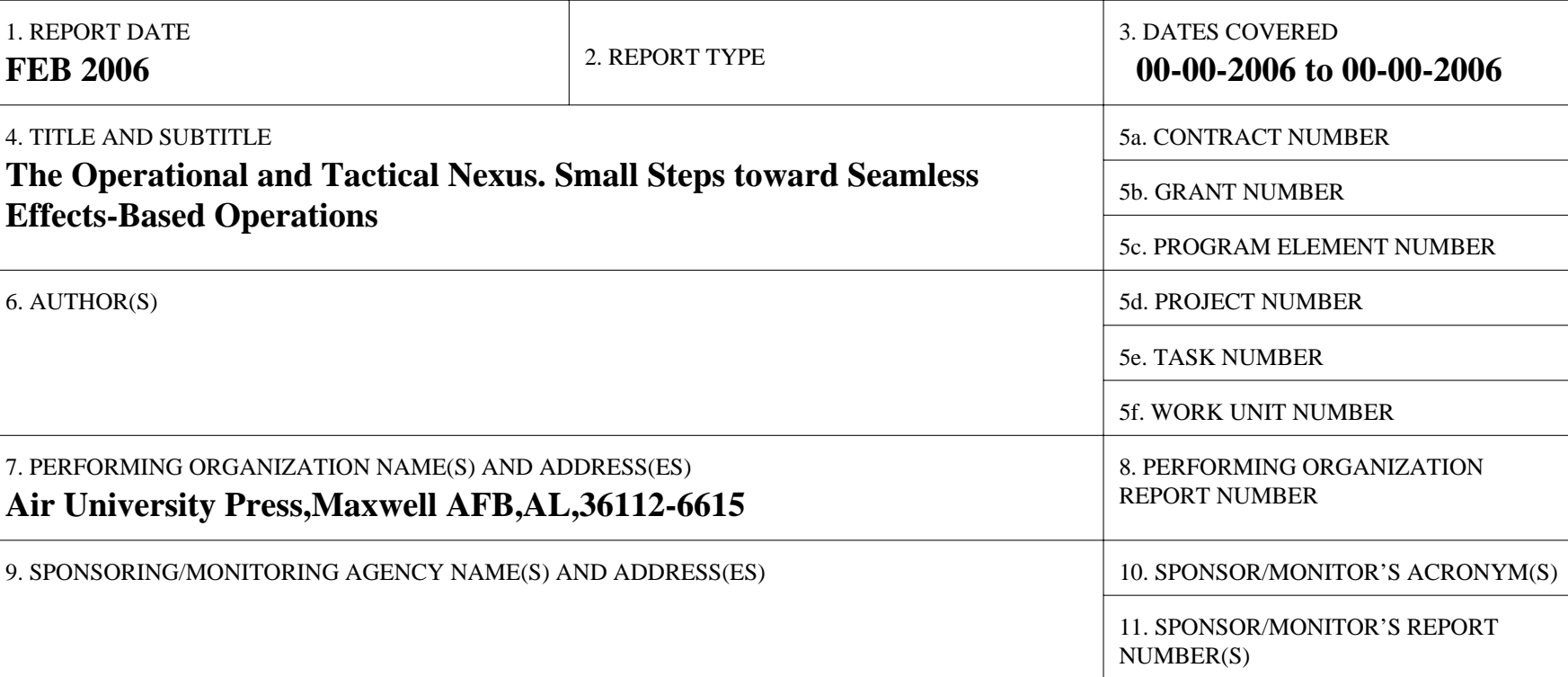

12. DISTRIBUTION/AVAILABILITY STATEMENT

Approved for public release; distribution unlimited

13. SUPPLEMENTARY NOTES

14. ABSTRACT

15. SUBJECT TERMS

16. SECURITY CLASSIFICATION OF:

\begin{tabular}{c|c|c}
$\begin{array}{c}\text { a. REPORT } \\
\text { unclassified }\end{array}$ & $\begin{array}{c}\text { b. ABSTRACT } \\
\text { unclassified }\end{array}$ & $\begin{array}{c}\text { c. THIS PAGE } \\
\text { unclassified }\end{array}$ \\
\hline
\end{tabular}

17. LIMITATION OF ABSTRACT

\begin{tabular}{c|l}
$\begin{array}{c}\text { 18. NUMBER } \\
\text { OF PAGES } \\
\mathbf{4 6}\end{array}$ & 19a. NAME OF \\
& \\
& \\
\hline
\end{tabular}


This Wright Flyer Paper and others in the series are available electronically at the Air University Research Web site http://research.maxwell.af.mil and the AU Press Web site http://aupress.maxwell.af.mil.

\section{Disclaimer}

Opinions, conclusions, and recommendations expressed or implied within are solely those of the author and do not necessarily represent the views of Air University, the United States Air Force, the Department of Defense, or any other US government agency. Cleared for public release: distribution unlimited. 


\section{Foreword}

Welcome to another in our series called "The Wright Flyer Papers." The Air Command and Staff College (ACSC) is pleased to publish our best student research projects each academic year. Our research program is designed to encourage our students to explore topics and issues aimed at advancing the application of air and space power and understanding the profession of arms. To that end, this series reflects our desire to perpetuate the intellectual spirit of early military aviation pioneers who availed themselves of time, here at Maxwell, to reflect solid research, innovative thought, and lucid preparation. Put another way, we think they are worth your time to read.

The Wright Flyer Papers reflect an eclectic range of doctrinal, technological, organizational, and institutional issues. Some research provides new solutions to familiar problems. Other studies highlight new opportunities and the benefits of their pursuit. By making these research studies available through the Wright Flyer Papers, ACSC intends to foster continued conversation amongst Airmen and fellow members of the profession of arms . . . a conversation that has helped create the most capable fighting force the world has ever known.

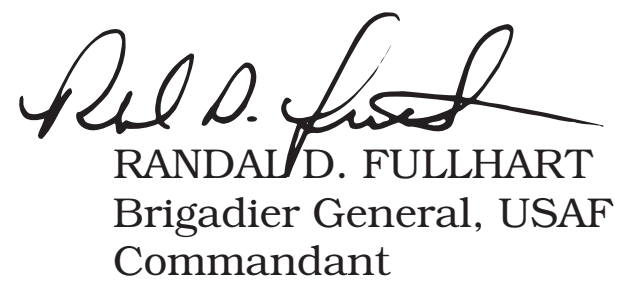




\section{Acknowledgments}

I would like to thank Col Anthony Cain-first, for allowing me to change research seminars so late in the game and, second, for allowing me to write on a subject he was dubious about from the beginning. I thank Chuck Colgrove of Air Combat Command (ACC)/Flight Operations and Training Branch (DOTO) for permitting me to use the mission essential competencies $^{\mathrm{SM}}$ concept developed by the Air Force Research Laboratory and ACC/DOTO. Finally, I would like to express my gratitude to past and current instructors of the USAF Fighter Weapons School. In the face of numerous outside pressures, they have remained true to their calling and produced graduates who are the heart and soul of the training programs that guaranteed victory after victory in the postVietnam era. They are the true keepers of the faith. 


\section{Abstract}

The literature on effects-based operations (EBO) seems to grow each day. Myriad definitions have appeared in service and joint doctrine writings as well as in other writings. Most are too far reaching for current capabilities, and they may be too far reaching for future capabilities. Both the United States Air Force (USAF) and the United States Joint Forces Command (USJFCOM) EBO definitions encompass all facets of national policy, including strategic outcomes. USAF and USJFCOM are attempting a quantum leap when smaller, more manageable steps are indicated to enable and embed an EBO culture in the planning community. Making the effort more difficult, service and joint doctrine writings often convey a sense of multipolarity when it comes to explaining EBO methodology. Joint planning doctrine is conceptually opposed to an idealized EBO methodology. Another impediment to EBO is a dichotomy in the way the USAF trains at the tactical level of war and the way EBO enthusiasts view campaigning at the operational level of war. One view focuses on events, missions, and platforms, while the other focuses on applying capabilities toward affecting systems and achieving a desired end state. The USAF purposefully evolved towards mission-based training programs following Desert Storm to link missions to combatant commanders' desired capabilities. Unfortunately, this change fosters the misperception that missions are capabilities and leads to inefficient force presentation to the combatant commanders. Finally, though service and joint doctrine writings strive to distinguish the three levels of war, the officers who will plan campaigns matured during a time when the lines became increasingly blurred. While it is clear that tactical actions can have strategic effects, the doctrinal desire to segregate levels and the institutional desire to view operational planning as completely distinct from well-founded and practiced tacticallevel effects-based thinking is limiting the evolution of EBO in the operational realm. Solving these mind-set differences and smoothing the disconnects at the tactical/operational nexus may hold the key to seamless effects-based operations in future joint fights. However, small steps, not quantum leaps, are required. 
This paper proposes two broad modifications to concepts and cultures to embed EBO at the critical nexus of the tactical and operational levels of war. Services, as part of the joint community, must narrowly define EBO in a quantifiable, measurable realm. The USAF needs to solve its tactical training/operational campaigning dichotomy by moving toward capabilities-based training. The services should stop clinging to the antiquated concept of separate and distinct levels of war with minimal similarities where no clear distinction actually exists. These small steps will build synergy between the execution of national policy and the planning that enables it. Such synergy may then aid the evolution toward the seamless continuum necessary for an EBO culture to thrive. 


\section{Introduction}

In this respect, recent attempts to develop and write joint military doctrine are helpful when their focus is on weapon systems capabilities and effects-based planning.

—Maj Gen David A. Deptula

The term effects-based operations (EBO) is banging its way into the lexicon. The United States Air Force (USAF) is wholly committed to the concept and is attempting to lead the other services along. Portions of the joint community, primarily the United States Joint Forces Command (USJFCOM), find merit in EBO and may increasingly consider it in planning for future operations. However, the USAF and USJFCOM are attempting a quantum leap when smaller, more manageable steps are indicated to enable and embed an EBO culture in the planning community.

Several obstacles impede the advancement of an EBO culture. Definitions of EBO are wide ranging and too encompassing for current capabilities. At times the definitions are even divergent in purpose. Arguments abound over whether EBO is simply a repackaged planning concept. The joint planning process seems at odds with the definitions and methods of EBO. Finally, there is an ongoing debate about whether EBO forms part of, as Maj Gen David A. Deptula says, a "change in the nature of warfare" ${ }^{1}$ or just a codification of the old ways in a new framework. Whether the concept is truly revolutionary, merely evolutionary, or just a new term for an old way is not important. Understanding service specifics and joint doctrine views of $\mathrm{EBO}$ is more applicable, but USAF and joint doctrine make this no easy task. Completely apart from the growing literature, service and joint doctrine writings often convey a sense of multipolarity when it comes to explaining EBO methodology. Joint planning doctrine, admittedly updated less recently than USAF doctrine, is conceptually at odds with an idealized EBO methodology, and it is unlikely to change significantly in the near future.

To make EBO a reality, the USAF must confront the dichotomy it created between the way it trains at the tactical level of war and the way it sees itself campaigning at the operational level of war. The tactical level focuses on 
events, missions, and platforms, while the operational level focuses on the application of capabilities toward affecting systems and achieving objectives. The USAF's training programs are tied to the way it reports its combat effectiveness via the Department of Defense's (DOD) combat readiness reporting process. This process represents the unit's primary mission(s) through the designed operational capabilities (DOC) statement. These missions become the basis of training and reporting combat "capabilities," which can lead to inefficient force presentation to combatant commanders. Not all aircraft flying a given mission are equally capable. Though the USAF purposefully evolved into a mission-based training program, it is making strides toward capabilitiesbased training that will allow it to more effectively communicate the war-fighting abilities of particular units. This capabilities-based approach to training at the tactical level aids EBO at the operational level by incrementally smoothing the boundary between the two and creating a culture of understanding about how capabilities lay the foundation for creating effects.

Joint doctrine, primers on $\mathrm{EBO}$, and intermediate developmental education instruction all go out of their way to illustrate the differences between the tactical and operational levels. Instead of adding clarity to the concept, these attempts act as tacit dismissals of tactical expertise. While joint and service direction should embrace the effects-based weaponeering process at the tactical level, they instead foster the idea that the operational level is something far above and previously out of reach of those officers who are experienced in using tactical methods and are moving into the "operational" stages of their careers. The idea rings hollow for midlevel officers coming of age in the post-Desert Storm era, partially because EBO has always been a part of their own training and partially because they recognize there is no longer a valid means of separating tactical actions from strategic effects. As such, it may be helpful to view the traditional levels of war through the filter of a new concept, one that sets strategic guidance apart but embraces the connection between tactical planning/execution and operational planning as the mechanisms of executing national policy.

Services must narrowly define EBO in a quantifiable, measurable realm. They should strive to link tasks to objec- 
tives where effects are more easily determined and quantified rather than the current strategy-to-task concept that is too far reaching for current assessment tools. The USAF needs to solve its tactical training/operational campaigning dichotomy, smoothing the lines at the nexus by moving toward capabilities-based training. Finally, the services should stop clinging to the antiquated concept of separate and distinct levels of war with minimal similarities where no clear distinction actually exists. These small steps will build synergy between the execution of national policy and the planning that enables it. Such synergy can then evolve into a seamless continuum necessary for an EBO culture to thrive.

\section{Effects-Based Operations-What Are They?}

Foremost in any discussion of $\mathrm{EBO}$ is the need to put the term in context, define what it is, and explain how it is used in planning and executing a joint campaign. Such an endeavor includes deciding on the evolutionary status of $\mathrm{EBO}$, wading through doctrine and the growing literature on EBO to find a working definition, and then looking at how EBO is supposed to fit into the joint force commander's (JFC) planning process. The idea is to help the reader understand the framework of $\mathrm{EBO}$ as the author relates its issues to the dichotomy between a tactical viewpoint and an operational one, on the one hand, and the blurring of the intersection between the two, on the other.

\section{New Trick or Old Hat?}

The argument over whether EBO constitutes a new way of thinking about warfare centers on what the application of force is supposed to achieve. Major General Deptula argues that Desert Storm marked the first use of parallel warfare, the ability to simultaneously affect an array of objectives, ${ }^{2}$ based on achieving specific effects instead of outright destruction. ${ }^{3}$ Essentially, he argues that EBO is focused on affecting systems to control an adversary-a departure from traditional attrition or annihilation strategies. EBO can control an enemy through viewing him as a system of systems where there is no need to destroy the entire system to 
render it useless or to degrade it to the point that it becomes inconsequential. A careful planner only needs to apply the force necessary to a portion of the system to affect its other parts. Whereas previous wars relied on sequential attack of centers of gravity to roll back the adversary's ability to continue the fight, the new warfare seeks to control an adversary through the swift application of effects-based parallel warfare. Major General Deptula states, "Using effects-based operations, the determinant of success is effective control of systems that the enemy relies upon to exert influence. . . . Changing the way we think about the application of force may produce more effective use of force."

Effects-based planning is as old as warfare itself. The Military Operations Research Society (MORS) puts it this way: "Consensus emerged that warfare, particularly effective warfare, has always been effects-based." More bluntly, Air Force Doctrine Document (AFDD) 2, "Organization and Employment for Air and Space Operations" (draft, 10 May 2004), states, "The effects-based approach is not new." Regardless, recognizing its context allows us to proceed with defining what EBO truly is.

\section{Defining EBO}

Even with the quantity of information available, defining effects-based operations is not easy. Consider the following excerpt from a MORS workshop on EBO: "In the words of plenary speakers at the Workshop, EBO therefore becomes 'a way of thinking' (Major General Deptula, USAF), 'a common frame of reference between DOD and other agencies' (Graham Kessler, J9, JFCOM), and it 'coordinates sets of actions directed at shaping the behavior of friends, foes, and neutrals, in peace, crisis, and war' (Ed Smith, Boeing). ${ }^{7}$ Not one of these tells us what EBO actually is or makes EBO distinct from any other method of planning for war.

Surprisingly little has appeared on the subject in joint doctrine. The term $E B O$ does not appear in any joint publication (JP) on planning (3 or 5 series) other than in JP 3-60, Joint Doctrine for Targeting. USJFCOM leads the joint community with an EBO white paper and a Joint War Fighting Center Doctrine Series pamphlet entitled "Operational Implications of EBO" and dated 17 November 2004. Perhaps 
not surprising, the USAF has written more on the subject than any other service. The draft AFDD 2 added significant sections discussing the concept and method of EBO. The following illustrates the various definitions and descriptions in service and joint doctrine writings.

All-encompassing, cumbersome EBO definitions abound. USJFCOM defines EBO as "operations that are planned, executed, assessed, and adapted based on a holistic understanding of the operational environment to influence or change system behavior or capabilities using the integrated application of selected instruments of power to achieve directed policy aims" (emphasis in original). ${ }^{8}$ In the words of the Institute for Defense Analyses, "Effects-based thinking requires the explicit and comprehensive linking of all actions to operational and strategic outcomes." 9 The items listed above in boldface must be separately defined to give the overall definition meaning. ${ }^{10}$ AFDD 1, Air Force Basic Doctrine, and AFDD 1-2, Air Force Glossary, define EBO more clearly as "actions taken against enemy systems designed to achieve specific effects that contribute directly to desired military and political outcomes." ${ }^{11}$ This definition is more direct, but it seems to leave out the USJFCOM ideas on planning, assessing, and adapting. It takes a reading of AFDD 1-2 to see that "actions" are expanded to mean "operations, targeting, or strategy." 12 Though this statement clarifies actions in the original definition, it unfortunately defines a term by using that term. Clarity does not always accompany succinctness.

The only joint publication that addresses EBO, JP 3-60, does not define it. JP 3-60 states that "effective targeting is distinguished by the ability to identify the targeting options, both lethal and nonlethal, to achieve the desired effects that will support the commander's objectives." ${ }^{13}$ The statement is listed in bold under the heading of "EffectsBased Targeting." Though this statement does not offer a definition, it does offer a narrower idea about what effective targeting does. This concept simply stops the effects linkage at assessable objectives. This causal linkage between actions and objectives is founded in EBO methodology, taking the strategy-to-task, objective-based joint doctrine planning process into the realm of EBO. ${ }^{14}$ However, linking targets to objectives is far less encompassing than true 
strategy to task. This view of targeting relies on commanders and subordinate commanders to generate objectives that link to overall strategy and an end state or desired outcome, but the targeting is effective when it generates the desired effect toward achieving objectives. Idealized EBO would link the targets themselves to desired outcomes. While this may be possible, as will be seen later, it is unnecessary and too far to reach during these early days of $\mathrm{EBO}$. If the commander's plan is adequate, attaining objectives should achieve the military end state that supports the directed policy aims. JP 3-60's description of EBO falls short of an all-encompassing, idealized EBO concept for achieving "directed policy aims." However, it clearly links effects to the commander's objectives. This simple concept is the key to moving steadily into EBO.

The definitions above relate effects to policy aims, strategic outcomes, and political end states. These are the Holy Grail for EBO enthusiasts and represent the idea that planners are capable of explicitly determining all the effects (second, third, nth order, cumulative, and cascading) of a given action. It is not at all clear whether this is possible in the near term or even in the long term. ${ }^{15}$ There are simply too many variables to manage in systems of systems ultimately controlled by human nature. Additionally, confirming the effects and ensuring the plan is achieving its objectives - the job of combat assessors and analysts-is currently beyond the capabilities of the analytical community. ${ }^{16}$ While efforts to change this fact are laudable and should continue, current planners and the political establishment directing the military must understand that their best efforts will fall short of EBO's idealized promise for the foreseeable future. For this reason, it is appropriate to narrow the scope, to take smaller steps versus attempting a massive paradigm shift before all the capabilities are in line. As one expert in joint targeting said, "We often apply overwhelming combat power, the adversary capitulates, and we do not know exactly why." ${ }^{17}$ That system is brute force and lacks finesse, but it often works. There is time to narrow the focus of EBO and refine the methods for future increasing analytical capabilities. This may aid EBO's acceptance in joint planning. 


\section{EBO and Joint Planning}

Definition ambiguity and a joint planning process that runs contradictory to an idealized effects-based methodology complicate planning at the operational level. The joint deliberate campaign planning process of JP 5-0, Doctrine for Planning Joint Operations, begins with the regional combatant commander assigning planning tasks to supported commanders, issuing planning guidance, and apportioning resources and forces to be used for planning purposes. ${ }^{18}$ The joint air estimate process (JAEP) begins the same way. ${ }^{19}$ As such, forces and resources are already apportioned before course of action (COA) development begins. The joint/coalition forces air component commander (J/CFACC) defines objectives for the planning staff to meet through the COA development process. JP 3-30, Command and Control for Joint Air Operations, alludes to the EBO concept by stating "the framework of operational objectives, tactical objectives, and tactical tasks provides a clear linkage of overall strategy to $\operatorname{task}^{20}$ (see appendix A). The statement is simple enough, but it does not tell the whole story.

In the purest sense, the EBO planning cycle allows the planner to anticipate a specific outcome, or policy aim, without constraints. The object should be to achieve the political end state while determining the means and capabilities needed to do so. Not surprising, the USAF embraces this view of EBO. As the draft AFDD 2 states, "The effects-based approach is about securing objectives, not about platforms, weapons, or methods. Such an approach starts with desired outcomes-effects and objectives-and then determines the resources needed to achieve them. It does not start with particular capabilities or resources and then decide what can be accomplished with them." ${ }^{21}$ While this view may be visionary, it does not exactly conform to the joint planning process. It also adds ambiguity by equating effects and objectives to desired outcomes. This is simply an overstatement of what effects and objectives are.

As noted above, the joint planning process begins with guidance from the combatant commander to include apportioning the force for planning purposes-a force that comes with preestablished capabilities. As JP 3-30 states, "COA development must take into account resource con- 
straints of the joint force at large." ${ }^{22}$ By the time deliberate or crisis-action planning begins, idealized EBO is already off the tracks. Though the process is iterative and the JAEP allows the JFACC to request additional resources during mission analysis, the JFACC may not be in a position to do so until well into the estimate process. In fact, AFDD 2 would submit that forces and resources are the last things the JFACC should consider.

Making matters worse, the draft AFDD 2 engages in doublespeak on capabilities, resources, and effects. In the pages following the emphatic statement that EBO does not apply capabilities and resources to see what must be accomplished, the document says, "Effects-based planning matches air and space component capabilities against the approved target list with a focus on achieving desired effects." ${ }^{23}$ Matching capabilities to targets to achieve a given effect is far different from defining the effects that lead to an end state and determining which targets and to what degree they need to be affected to achieve the desired outcome. This is not a simple matter of semantics. In fact, the two cases are 180 degrees out of phase. Recognizing this result requires some knowledge of the joint targeting process.

Most joint target lists (JTL) are produced before or in conjunction with deliberate planning long before hostilities arise. JP 3-60 defines the JTL as "a consolidated list of all targets considered to have military significance in a combatant commander's area of responsibility (AOR)." ${ }^{24}$ The lists are compiled without regard for particular objectives and in the absence of any campaign plan. They are simply targets of "military significance." They also form the basis of every target list to follow and finally conclude with a daily joint integrated prioritized target list (JIPTL) recommended by the joint guidance and apportionment team (JGAT), now referenced as the targeting effects team (TET) in Air Force Operational Tactics, Techniques, and Procedures (AFOTTP) 2-3.1, and approved by the JFC. In essence, planners take a list of prepublished targets, select those that will affect daily objectives as laid out in the air operations directive, allocate preapportioned forces (and their capabilities) on the air tasking order (ATO), draw conclusions about what effects are supposed to take place due to the strikes, and then relate those back to objectives and strategies in the joint air 
operations plan (JAOP). It is as if planners were injecting "effects" into the middle of the cycle instead of beginning with them in the "holistic" way envisioned by USJFCOM. The TET is not doing effects-based targeting; it is doing effectsbased allocation. In fact, the redesignation of the JGAT to the TET seems an admission that this is how the process works in reality.

In a final example of service schizophrenia, the USAF's College of Aerospace Doctrine, Research and Education's (CADRE) Joint Air Estimate Planning Handbook states that "EBO is an approach . . . that focuses on . . military activities for the effects they produce rather than the targets or even objectives they deal with. In short, it focuses on desired effects more than on merely attacking targets or simply dealing with objectives" (emphasis in original). ${ }^{25}$ The line is completely contrary to the joint planning process, making effects an end unto themselves. In reality, a planner cannot separate the target or action from the effect. No force attacks targets without a sense of what it wants to achieve. Though the grueling mechanics of the ATO cycle drive planners to lose sight of effects and objectives during exercises, JIPTLs now explicitly relate tasks to JAOP and JFC objectives. ${ }^{26}$ The CADRE handbook, in attempting to divorce effects from objectives, makes them an end unto themselves. This directly opposes the essence of EBO, is contrary to joint planning, serves to cloud EBO issues, and stifles productive experimentation in the EBO realm.

No doubt the term $E B O$, if not the concept, is ambiguous in service and joint doctrine. Official writings on the subject often seem divergent and circuitous. Current joint planning doctrine is at odds with the unconstrained, idealized view of EBO held by the USAF and USJFCOM. The larger issue may be that reality is at odds with such a view. It is hard to imagine a planning environment unconstrained by preapportioned resources and capabilities. The secretary of defense went on record with Reserve Army troops in Kuwait as saying that "You go to war with the Army you have, not the Army you want." ${ }^{27}$ No less true is the idea that you plan within the constraints of available forces and the capabilities they lend to the fight. Services and the joint community must first decide what EBO really means. They should pare it down from the broad ideas about linking end states to tac- 
tical tasks and simply link tasks to operational objectives. It is a smaller step that may lay the foundation for broader perspectives to come, perhaps when the analytical community is capable of the assessment and predictive analysis required to make the USAF's dream a nearer reality.

\section{The Tactical Training/Operational Campaigning Dichotomy}

Another impediment to the realization of true $\mathrm{EBO}$ is the dichotomy between the way the USAF trains and executes at the tactical level of war and the way it desires to plan and campaign at the operational level. Maj K. Noedskov, Royal Danish Air Force, observes:

For the pilot CAS [close air support] [and] AI [aerial interdiction] . . . are excellent descriptions of the missions he is about to conduct. . . . However for the operational level commander CAS [and] AI . . . are bad ways of describing the campaign the commander is about to conduct to achieve the desired effects. ${ }^{28}$

Missions do not describe effects or capabilities, but they are the basis of tactical training. That training is driven by the combat readiness reporting process that equates capabilities to missions. Though the beginnings of a capabilities-based training program are now in their infancy, the Air Force must continue this progression and change its training culture to fully exploit EBO.

\section{Training as a Function of the Reporting Process}

Contrary to the common mantra that the USAF trains like it plans to fight, it actually trains to report its readiness to fight. The common system across the DOD that serves as a "registry of all operational units" is the status of resources and training system (SORTS). ${ }^{29}$ This system has three primary purposes: "It provides data critical to crisis planning; it provides data for the deliberate planning process; and is to be used by the CSAF and subordinate commanders in assessing their effectiveness in meeting their Title 10, United States Code responsibility." ${ }^{30}$ Units are required to report their C-status, a measure of their ability to execute their wartime mission(s). These missions are defined on a DOC 
statement, the purpose of which is to "summarize and provide source information for the mission(s) for which the unit is organized or designed." ${ }^{31}$ While there is opportunity to list tasks, purposes for missions, and special capabilities, there is rarely room to break missions into individual tasks or capabilities. ${ }^{32}$ This deficiency has led to an idea throughout the DOD that mission and capability are equal.

DOC statements drive combat air forces' (CAF) resourcing and training. SORTS supports the service chiefs' responsibilities to "organize, train, and equip forces for use by combatant commands." 33 Major commands use information on DOC statements to determine different types of resources for their units, including weapons allocations, flying hours, spare parts, and rotations to live-fire deployments and exercises. As a commander evaluates his or her unit's readiness for wartime tasking, the commander must also focus training on missions represented on the DOC statement and reported through SORTS.

Consider the sample DOC statement from Air Force Instruction (AFI) 10-201, Status of Resources and Training System, for the 55th Fighter Squadron in appendix B. In section II, "Mission Identification," the mission tasking narrative lists all the missions the unit is capable of flying. On the following page, missions are related directly to the basis for the training measured area C-status. While numerous capabilities comprise a mission such as Suppression of Enemy Air Defenses (SEAD), they are not listed individually. Examples may include detection of enemy Integrated Air Defense System (IADS) emissions, location of enemy IADS, and destruction of enemy air defense systems by way of general purpose, inertially aided, or laser-guided bombs (LGB). These capabilities more correctly and discretely relate the kinds of tasks a JFC, through the JFACC, can use to achieve certain effects in the air superiority realm. However, forces are not presented to the JFC with any relation to these actual capabilities from the DOC statement. Although combatant commanders do not use DOC statements to task units (unit type codes do that through AFI 10-201), the information is available across the DOD, and unit taskings under current operation plans and concept plans are shown on the DOC statement. This can lead to suboptimum force presentation and apportionment. 
F-15E, F-16, and A-10 squadrons may have CAS on their DOC statements, but not all platforms have the same capabilities in the CAS arena. Until recently, A-10 units were incapable of guiding LGBs with onboard systems, and none can operationally employ inertially aided munitions (IAM) like the joint direct attack munition. They do have large payloads, and their flight regime favors the constrained airspace that is the norm during CAS missions. F-15Es have much longer loiter times and can carry more ordnance than F-16s. However, due to lower numbers and their unique abilities to carry certain weapons more suited to AI or strategic attack target sets, they may be better allocated to other parts of the JAOP. Some F-16s have IAMs and LGB capability but may lack range and/or loiter time for AORs with basing rights issues, and none have the payload of either F-15Es or A-10s. These platform-specific capabilities and limitations are not likely to show on any DOC statement. However, they clearly represent discreet capabilities that should be used in planning for effects during operations of varying objectives in diverse AORs and situations. Missions are not equal to capability, yet the reporting process makes it appear that they are.

\section{Evolution to Mission-Based Training}

The Air Force purposefully began to focus training on missions and to report those as capabilities to the combatant commands in the midnineties. The CAF oversight program for training combat aircrews was then called graduated combat capability and was focused on events that were "the right skills for our aircrew to have." ${ }^{34}$ According to the Primer for Ready Aircrew Program (RAP), published by Air Combat Command (ACC) at the initiation of the current training program, there was an underlying assumption that effective training meant logging events, which was the key to reporting combat-ready status. ${ }^{35}$ However, it was easy to skew the readiness numbers. For example, a pilot could log a missile shot on a cross-country sortie, get a tally on an airliner, and call the mission a successful intercept sortie. Additionally, the flying-hour programs for CAF units were generated based on the MAJCOM-approved utilization rate for the aircraft assigned. The penchant for square-filling, 
along with a discrepancy in the way SORTS and a utilization rate-based flying-hour program required reporting for mission readiness, led to a change in the way the CAF conducts training. ${ }^{36}$

In 1996 the CSAF directed a change to CAF training. In that tasking, the chief laid out three requirements: "Develop a train-to-task process; provide an inextricable link between commander in chief (CINC) requirements, flying training, and readiness indicators; [and] model requirements accurately." ${ }^{37}$ It was a laudable goal whose end would be an inextricable linkage of missions to combatant commander requirements expressed by way of the DOC statement. Theoretically, the joint mission essential task list (JMETL) flowed directly into the RAP tasking message to individual units through the Air Force mission essential task list and Air Force missions. The RAP publication stated, "This leads directly to your unit's training program, specified in the RAP tasking message and your training plan, from which we derive your flying hour program. Successful execution will provide combat readiness for the CINC." ${ }^{38}$ RAP tasking messages were to reference the JMETLs that were to be carried on to the DOC statements for tasked units. Those references are no longer explicitly stated. ${ }^{39}$ Instead, RAP tasking messages list required sorties by missions firstnot exactly a train-to-task mentality. For example, the F-16 Block 50 tasking message grants the largest apportionment of sorties to SEAD. ${ }^{40}$ While it does task a number of events that may be called capabilities, "Dynamic A/A [air-to-air] targeting" is one such listing; most of the others are just events such as Have Quick or electronic protection use. ${ }^{41}$ The key is that events adding to the combat capability can only be logged during a RAP sortie-a sortie qualifying as a RAP mission. ${ }^{42}$ RAP related capability to mission by saying RAP would take "those capabilities . . that ACC units can provide, and . . . match . . . what the CINC needs by placing those missions you can provide to your apportioned theater

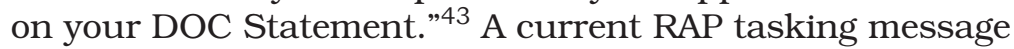
makes the mission/capability linkage more explicit by stating commander option sortie allocation on combat missionready aircrew-frontline squadron flyers as opposed to attached aircrew working group or wing jobs-will be "only DOC tasked missions." ${ }^{44}$ Mission-centric training is well 
entrenched in the USAF. ${ }^{45}$ The future of true capabilitiesbased training is unclear.

\section{Beyond Mission-Based Training}

Recently, in coordination with the Air Force Research Laboratory (AFRL), ACC undertook a project to further refine the tactical tasks of joint campaign planning and attempted to define the true capabilities of the war fighter. Where the tactical task of "destroy $80 \%$ of the IADS's Command Centers" from appendix A ends, tactical training actually begins. War fighters must accomplish a myriad of individual tasks to achieve this higher-level tactical task. Some of the tasks are specific to aircraft and missions. Others span all missions and platforms. Fire control coordination measures through JP 3-09.3, Joint Tactics, Techniques, and Procedures for Close Air Support, are one example of specific knowledge sets and tasks applicable to the single mission of CAS in all the platforms that perform it. To really understand the pickle button to the grand strategy linkage the Air Force so desires, much more work is needed in defining that enormous area of capabilities and tasks directly beneath the operational planner's tactical tasks. It is possible for a fighter aircrew member to become a master of all missions by training to a correctly defined set of minitasks or skill sets-what the author dubbed the "Fighter Quanta." ${ }^{46}$ It is a way to bridge the gap between true human-level capabilities and the limited, dogma-entrenched missions reported on DOC statements.

ACC and AFRL defined these minitasks in what they called mission essential competencies ${ }^{\mathrm{SM}}$ (MEC) and the knowledge, skills, and experiences (KSE) that accompany them. ${ }^{47}$ These MECs ${ }^{\mathrm{SM}}$ went into the F-15C RAP tasking message for the first time in fiscal year 2005. ${ }^{48}$ They are a good first step and are a combined effort of training professionals from the ACC staff, the USAF Weapons School, and AFRL; but there is room for improvement-they are still rather broad. For example, "detects factor threats in the area of responsibility" is one of seven SEADs ${ }^{49}$ In a flight briefing, that would be listed as an objective, while the rest of the brief would explain the tasks to accomplish it. These tasks and the continuing search for commonality among 
missions can aid the idealized strategy-to-task concept of joint planning and EBO. Interestingly, this SEAD MEC ${ }^{\mathrm{SM}}$ is similar to the air-to-air MEC ${ }^{\mathrm{SM}}$ "detects factor groups in the area of responsibility." ${ }^{50}$ While there are obvious differences in smaller, more discreet cockpit tasks that go into the two types of sorties, the similarities in these competencies for diverse missions lend credence to the possibility of linking tactical tasks and cockpit minitasks to create holistic weapons system capabilities across all missions. This should be the goal of every CAF training program, since it will only increase the war-fighting capability of the USAF.

In the spring of 2003 , the F-16 squadron at the USAF Weapons School completely redesigned its syllabus by divorcing syllabus missions from discreet skills, dubbed skill sets, required of F-16 weapons officers. This approach allowed a relatively unbiased look at what the end product should be capable of outside the human tendency to resist change and hold on to favorite syllabus sorties. The instructors at the F-16 Weapons School developed skill sets with slightly higher fidelity than the KSEs beneath the MECs ${ }^{\mathrm{SM}}$. The tasks were more distinct; the skill sets more closely approached the Fighter Guanta concept alluded to above and discussed in the Weapons Review. The Weapons Instructor Course (WIC) syllabus is only a small subsection of CAF training, while the beast that the AFRL and the ACC's training branch is attempting to tame is far larger and more complex.

Both approaches are valuable for developing cockpit skills that become capabilities. These capabilities, used in support of achieving tactical tasks and operational objectives, smooth the seam in the dichotomy between tactical training and operational campaigning. That training professionals found similar competencies across diverse missions highlights a trend in the correct direction for capabilitiesbased training programs and away from mission-centric thinking - steps toward the ultimate and essential dislocation of capabilities and missions.

The Air Force must change its training culture. Presently, it trains to report its combat status within the framework of SORTS by training to missions and presenting them as capabilities to the combatant commander. Perhaps SORTS reporting and the DOC statement should do away with the mission identification sections and directly report capabili- 
ties. This would create a much larger document but would add far more detail. Perhaps a further refined JMETL process would be a good place to start by detailing quantifiable capabilities necessary to execute combatant commander tasks. Processes such as the one that produced the MEC ${ }^{\mathrm{SM}}$ concept and F-16 WIC syllabus revision are valuable tools to guide this effort at the joint level. Much as the F-16 WIC divorced syllabus missions from weapons officer skill sets, it is up to Airmen to break the mission/capabilities linkage we created. The JFC must understand that F-16 or F-15E CAS is not the same as A-10 CAS. The RAP Primer stated, "Relating events to flying hours is difficult, and at the same time relating events to supported CINC mission requirements was also difficult." ${ }^{51}$ That may be true. However, a combatant commander thinking only in terms of mission is not thinking about effects, and relating events to missions says nothing of capabilities. Difficult thinking is required if the tactical training/operational campaigning dichotomy is to be broken.

\section{The Levels of War: Myth, Model, or Maze?}

Joint doctrine clearly lays out three separate and distinct levels of war that, when viewed in this manner, slow the progression of EBO. Understanding exactly where one level ends and another begins is similar to walking through a maze that endlessly turns on itself. In some sense, the levels of war are less a model for a wide spectrum of military actions than they are a myth. To be sure, an expert tactician cannot successfully plan a large campaign without broadening his or her perspective into the operational realm. However, that same planner cannot forsake all the learning about how to think and operate tactically and expect to succeed. Doctrine's desire to separate the levels of war clashes with experience and well-founded tactical thinking. Additionally, as any unmanned aerial vehicle pilot or 20-year-old Marine with a journalist in tow during a firefight will tell you, there is no longer such a thing as a purely tactical action. Distinct definitions have little meaning. The joint community and doctrine attempt to distinguish between the three levels of war. But campaign planners should cling to the 
value of well-developed, tactical effects-based thinking and recognize there is no longer such a thing as a differentiation between levels of war.

\section{Doctrinal Views on the Levels of War}

Both joint and Air Force doctrine go to great lengths to separate ways of thinking about military operations into three distinct categories called the levels of war. The definitions of strategic, operational, and tactical levels of war from JP 1-02, Department of Defense Dictionary of Military and Associated Terms, are included in their entirety at appendix C. At the tactical level, "Battles and engagements are planned and executed to accomplish military objectives assigned to tactical units or task forces." 52 This level is focused on the "arrangement and maneuver of combat elements" with respect to each other and the enemy to "achieve combat objectives." 53 The operational level is where "campaigns and major operations are planned, conducted, and sustained to accomplish strategic objectives" ${ }^{44}$-a doctrinal blurring of the lines in the definition. This level introduces operational objectives to link tactical actions with strategy and is focused on "sequencing events to achieve the operational objectives, initiating actions, and applying resources to bring about and sustain these events" that imply a broader scope of time and space than tactics. ${ }^{55}$ At the strategic level of war, the nation's security objectives and presidential guidance determine national military objectives. ${ }^{56}$ JP 1-02 points out that "activities at this level . . . sequence initiatives; define limits and assess risks for the use of military and other instruments of national power [and] develop global plans or theater war plans to achieve these objectives. ${ }^{~}{ }^{77}$ It is helpful to break the definitions down further and look at key words.

The true doctrinal distinctions between the levels of war may be understood better as execution for combat objectives at the tactical level; planning to achieve linking objectives at the operational level; and guidance and direction to achieve global or national objectives at the strategic level. Tactical operations occur where maneuver units execute combat to achieve immediate and near-term objectives. The operational level is about planning event sequences to link 
combat to strategic objectives. This level is simply where national objectives or direction from the civil command authority become a plan to use the national instruments of power (IOP). The strategic level is concerned with providing guidance or direction to achieve national goals. The civil command authority assesses risk and gives guidelines for employment of the IOPs. This seems straightforward, but the connotation of levels and apparent application of the concept only to war cause ambiguity. The former creates an aura of distinct boundaries where expertise at one level might be viewed as limited or irrelevant in others. The latter seems to limit the concept solely to the military IOP.

It is unlikely that a fully holistic EBO methodology can take hold in the US political environment. National strategy provides the construct for planning that creates the concept for execution. However, if the USJFCOM definition of EBO takes hold, this approach becomes antiquated as it lacks a holistic view toward achieving national objectives. The holistic approach implies that policy makers not exclaim that "the policy is X; now find me the means to make it happen." While it would be well for policy makers to be versed in an idealized EBO culture, the limitations of such a system were highlighted above in the example of Secretary Donald Rumsfeld's trip to the AOR. When questioned about the possibility of military action in response to Iranian nuclear ambitions, Gen Richard B. Meyers, USAF, replied that "the president makes policy and the military is prepared to carry it out." ${ }^{58}$ Though this would be an extremely difficult task for a military spread as thinly as it is in the Global War on Terror, the former Joint Chiefs of Staff chairman publicly recognized that if told to take action, the military's job is clear. It illustrates the one-way street that is policy direction to military strategy and is decidedly not an effective EBO methodology. For this reason, there may be a better representation for concepts similar to the levels of war that can remove some of the ambiguity, aid the progression of $\mathrm{EBO}$, and apply it to all forms of national power.

The levels of war may be viewed better as modules of national policy. These modules are execution, planning, and direction (see a graphic depiction of the concept at appendix D). Direction is set apart from the other two, though linked by objectives, and is concerned with policy making 
at the national level. The other two are intricately linked within the IOP and deal with carrying out policy. This concept more accurately represents the differences between governing guidance regarding policy and the mechanisms that make the policy a reality. It more closely relates those mechanisms necessary for overall success-planning and execution-within the IOP. Rather than seeing tactics and operations as two fully distinct levels, the module concept explicitly ties together planning and execution. Due to the limitations of the holistic and idealized EBO process noted above, it is better to focus EBO energies more narrowly on the planning and execution modules of policy as the concept shows in appendix D. Here, EBO can be effective in linking execution to planning and planning to the linking objectives derived from policy makers' direction. In this way, planning and execution are seen as parts of the whole rather than as distinct levels. In this nexus EBO can thrive.

\section{Embracing the Value of Tactical-Level Effects-Based Thinking}

We currently have at our disposal a proven effects-based thinking methodology and a core of officers who are trained in its use. Unfortunately, due to a false requirement to separate the tactical level from the operational level, EBO is not viewed as the building block to broader campaign-level effects. Our military force grows leaders "from the ground up." Line lieutenants do not show up to a joint air operations center and begin recommending apportionment. They begin as platoon leaders, wingmen, or junior intelligence officers. This foundation eventually grows leaders at the broader and higher levels of military operations. Young tacticians learn the art of small-unit maneuver, the military decision-making process, surface warfare, and weaponeering for desired probability of destruction $\left(\mathrm{P}_{\mathrm{d}}\right)$. These tactics of the execution module of policy place the US military beyond comparison throughout the world. However, doctrine for campaign planning, the vast literature on $\mathrm{EBO}$, and even intermediate developmental education institutions have tacitly dismissed such knowledge and experience as it applies to planning military operations at the campaign level. It guarantees reinvention of the wheel. A better option is for the joint com- 
munity to embrace tactical-level effects-based thinking and integrate its methodology into campaign planning.

On the first day of orientation at the Air Command and Staff College, a speaker attempted to illustrate the students' embarkation on a new career phase. He said he did not care how good we were tactically-that it no longer mattered. He told us we were there to learn about being operational leaders. ${ }^{59}$ During a recent syllabus exercise in creating a JAOP, a facilitator and instructor at the Air Force's AOC replacement training unit embraced the idea of taking away majors' weapons school patches and reissuing them only when the wearer demonstrated knowledge in planning air operations. ${ }^{60}$ Consider this note in the USJFCOM EBO pamphlet: "The use of the word 'effects' in an EBO context describes the potential conditions of PMESII [Political, Military, Economic, Social, Infrastructure, Information] systems in the operational environment, not the immediate target effects of weapon systems or tactical-level actions." 61 These distinctions and the implied dismissal of tactical expertise should not exist and will only hurt the embedding of an EBO culture in the USAF and joint communities. Certainly, PMESII systems effects are different in magnitude, but they flow directly from immediate target effects. In fact, sometimes they are exactly the same. The speakers should have said, "Your tactical expertise, experience, and knowledge are absolutely essential to understanding the broader aspects of campaign planning and execution." The USJFCOM pamphlet should have been linked to higher-level effects by stating that "immediate target effects and the methodology for determining them have a direct impact on the operational environment of PMESII." These thoughts enable EBO planning by tactical experts.

Since the author's commissioning in 1990, effects-based thinking has been involved directly in mission planning and execution. In the $\mathrm{CAF}$, mission planning begins with the commander's intent and objectives for a given mission. That intent involves the level of destruction or incapacitation the commander expects to achieve by attacking the target set. Mission planning begins in earnest with target analysis in relation to the desired level of destruction. This analysis focuses on target vulnerabilities, critical nodes, and target sets. The planner attempts to find a vulnerability that will 
gain the maximum effect to achieve the commander's intent with as little force as possible. The planner seeks efficiency and economy of force because it leads to flexibility for the primary target and the ability to impose more damage to other targets or systems. Once the critical vulnerabilities are known, the planner weaponeers the individual impact points against various forms of ordnance to find the optimum match for the level of destruction required. This may include different forms of guidance, different bomb bodies, various fuzing options, or even mixed ordnance within a flight. The weapons effects needed to achieve the $\mathrm{P}_{\mathrm{d}}$ also drive the release parameters and target-area tactics that drive the ingress tactics and support requirements (SEAD, tankers, etc.). These-in turn-drive the package composition, takeoff times, and mission brief time all the way back to the planning timeline. This is the very essence of EBO.

EBO is well known to every CAF mission commander if not every flight leader and wingman. EBO takes a commander's intent and applies a logical, quantitative method to design a specific mission to achieve it. It is the natural way of the world for officers reaching the operational levels of their careers. Major General Deptula's thoughts about planners thinking only in terms of destruction are from an earlier time. ${ }^{62}$ As the weaponeering process above shows, pure destruction never enters the discussion unless that is the commander's intent. Tactical-mission planners do not think only in terms of outright destruction. Futhermore, those who will plan air operations will find pure destruction as a strategy of war to be beyond their experience.

Doctrine and senior leaders must embrace the tactical expertise of those who will be doing joint planning in an EBO construct. Separating the two or discounting their expertise will only harm the development of EBO. Certainly, most senior leaders understand this, and recent CFACCs have made every effort to stack their combined air operations centers $(\mathrm{CAOC})$ with weapons school graduates and other tactical experts for use in planning air operations. ${ }^{63}$ Highlighting the similarities between tactical weaponeering and EBO planning is far more productive than attempting to separate the tactical and operational levels. Officers at this critical juncture in their careers certainly see more similarities than differences in the nexus. They have also grown up 
during a time when single actions or immediate target effects can impact the strategic and political environment.

\section{The Dissolving Tactical Action/Strategic Effects Distinction}

There may have been a time when tactical actions rarely had direct impact on the political environment, but there are no officers on active duty today who have seen it. It may be another military myth that Desert Storm was the first time an individual action had strategic consequences, but one needs only to look back to My Lai or the photo of the South Vietnamese police officer executing a suspected Viet Cong irregular to recognize the fallacy of this belief. Any individual action can have far-reaching ramifications-another reason the levels of war do not have much meaning to those midlevel officers beginning the operational stage of their careers. For a cadre of military officers whose careers have matured in the post-Desert Storm era of 24-hour news cycles, the separation between tactical actions and strategic effects is nonexistent. This serves to illustrate the efficacy of tactical-level effects-based planning methods in campaign planning and the reality of blurred lines between the levels of war. However, since most examples of individual actions having strategic consequences were due to unintended effects, it says little of a current ability to plan in an idealized EBO construct.

Every member of the US armed forces is fully aware that individual actions can have global consequences. A wellknown example of such an event was the bombing of the $\mathrm{Al}$ Firdos bunker during Desert Storm. By all intelligence estimates, the bunker was a valid military target, a command and control bunker where high-level Baath Party leaders often gathered. LGB technology allowed a precision strike that would have been impossible less than two decades earlier. Unfortunately, coalition intelligence was not sufficient to discover that the bunker was often used by Iraqi civilians. Over 100 bodies were pulled from the rubble of the bombed-out bunker under the intense light of the world media. Despite the validity of the target and highly effective tactical execution, the coalition could not stand the unintended effects of killing innocents. Targets in Baghdad were 
virtually wiped clean from the coalition target list and were, from then on, only approved at the highest level. ${ }^{64}$

Consider one more example: days before Operation Iraqi Freedom was to begin, two F-117s streaked over Baghdad in early daylight attempting to decapitate the Baath regime by killing Saddam Hussein himself. The mission was flown with minimum planning and far later into daylight than any F-117s before had flown a combat sortie. It was done before any systematic degradation of the Iraqi air defenses. ${ }^{65}$ The mission was an abject failure. However, this one sortie had the potential of achieving the primary objective of Iraqi Freedom with a fin kit and 2,000 pounds of tritonal bomb casings. A regime change would have occurred had Saddam been sitting peacefully in the restaurant as it turned into masonry dust. A single conventional weapon can achieve national objectives. This is the world and the military we serve in. The sooner policy makers and planners understand this fact of twenty-first-century warfare, the faster EBO concepts will evolve and flourish.

The levels of war, while a viable model for thinking about warfare in the past, are a myth today. This conceptual framework hinders the progression of EBO methods because of a perceived need to separate these levels and distinguish them from the others. It creates a sense that the value of expertise in execution, particularly in capabilities and effectsbased weaponeering of individual targets, is lessened-that operational planners have to think differently. In reality, they have to think the same way in a broader scope. Finally, any officer likely to be planning or executing campaigns understands there no longer can be a differentiation between tactical actions and strategic effects. When one weapon can satisfy a policy goal or alter the course of a campaign, the levels of war as distinct entities are extinct.

\section{Conclusion}

Unfortunately, nine years after CSAF guidance to "Develop a train-to-task-process, provide an inextricable link between CINC requirements, flying training, and readiness indicators, [and] model requirements accurately," 66 the USAF is only marginally closer to the goal. The term EBO is cloaked 
in ambiguity. Joint doctrine, Air Force doctrine, AFOTTPs, and manuals used to instruct the air-estimate process verge on circular logic and are often disjointed. Clearly, the joint community must decide on a working or workable definition of EBO before it can be fully integrated into the joint planning process. The focus should be narrowly defined in the near term as relating operational/planning objectives to execution tasks, as they are in JP 3-60. The joint community needs to grow into the concepts, while the analytical means to an idealized EBO process still lie in the future. The Air Force must be wary of overreaching in this arena by making sweeping statements that claim a focus on desired outcomes rather than by simply linking apportioned capabilities and effects to operational objectives. The TET executes effectsbased allocation, and during these initial steps into EBO, that may be all we are capable of. EBO is not something the Air Force should shy away from, nor should it claim a capability to do any more. The Air Force is starting, as Major General Deptula says, "a way of thinking” about warfare. At present, an unconstrained EBO methodology is neither practical, possible, nor in accordance with joint doctrine. As the joint community gets more comfortable with it, however, the EBO concept will naturally grow into an iterative process of linking strategic guidance to commander's intent to objectives to tactical tasks to the competencies, knowledge, and skills necessary to accomplish those tasks. To put it in terms a fighter pilot understands, the challenge will be to raise a generation of young officers who understand the linkage between the pickle button and grand strategy. Along those lines, training concepts must evolve away from mission-centric paradigms.

For EBO to ever truly take hold, the Air Force must change its training culture. The focus of campaign planning is on capabilities that generate effects to support objectives, while the Air Force trains for missions and presents them as capabilities to the combatant commander. These are two disparate ways of thinking. Recall what Major Noedskov said of missions- "they relate for the pilot what he is about to accomplish, but they say little about how the operational commander achieves his objectives." It is up to Airmen to break the linkage between mission and capabilities that the Air Force created. The JFC must understand that A-10 
CAS is not the same as F-16 or F-15E CAS. Recent moves toward capabilities-based training are encouraging and necessary processes if the Air Force is to be successful in breaking the linkage. More efforts along these lines can further refine the tactical tasks into actual cockpit tasks that give our aircrews essential competencies to bring capabilities to the joint fight. These efforts can lay the foundation for the all-encompassing vision of EBO the Air Force desires to achieve-the ultimate linkage of discreet, missionindependent cockpit minitasks to grand strategy. Such a continuum also recognizes the limitations of the current model of the levels of war.

The conceptual framework of the levels of war and the perceived need to separate and distinguish them hinder EBO progression for a generation of officers who recognize the concept is extinct. The modules of national policy concept can highlight the distinction between setting national policy and the IOPs that carry it out. At the same time, it can highlight the interrelatedness of tactical actions and operational planning instead of attempting to set them apart. EBO can thrive at linking execution to planning and linking planning to the connecting operational objectives between direction/strategy and the IOP responsible for carrying out policy. This concept is a far more quantifiable realm and one better suited to the growth of the EBO concept. A narrowly focused $\mathrm{EBO}$ can benefit from current effects-based planning methods at the execution level.

There is inherent value in the expertise of execution and capabilities/effects-based weaponeering; operational planners would do better to think more like tactical-mission planners than to attempt to set themselves apart and above. This new way of thinking about warfare is not about thinking differently for the generation of officers raised in an effects-based tactical planning culture. It is about stepping off from that solid foundation and applying similar methods on a broader scope.

The juncture of the tactical and operational or the merging of execution with planning is the focal point that will enable an EBO culture. The time has passed for arguing over EBO's status as a revolution; the time also has passed for overstating abilities and grandly claiming an all-encompassing method. How the USAF and USJFCOM approach 
EBO will likely determine whether its full promise ever can be reached. Continuing along the same path surely will spell its demise, as the tools for predictive analysis do not yet exist. Taking small, narrowly focused steps, solving existing dichotomies, and recognizing the similarities involved in carrying out national policy serve as the best chance at laying the foundations for the USAF's EBO dream. Embracing a continuum, particularly at the tactical and operational nexus, is the key to EBO.

\section{Notes}

(All notes appear in shortened form. For full details, see appropriate entry in the bibliography.)

1. Deptula, Effects-Based Operations, cover.

2. Ibid., 4.

3. Ibid., 3.

4. Ibid., 18.

5. Hayes et al., Analyzing Effects-Based Operations Report, 2.

6. AFDD 2, draft, Organization and Employment for Air and Space Operations, 73 .

7. Hayes et al., 2.

8. United States Joint Forces Command (USJFCOM), Joint Warfighting Center Joint Doctrine Series Pamphlet 7, 2.

9. Gleeson et al., New Perspectives on Effects-Based Operations, 6.

10. USJFCOM Pamphlet 7.

11. AFDD 1, Air Force Basic Doctrine, 98.

12. AFDD 1-2, Air Force Glossary, 26.

13. Joint Publication (JP) 3-60, Joint Doctrine for Targeting, I-5.

14. Mann et al., Thinking Effects, 2.

15. For a discussion of cascading, direct/indirect, and nthorder effects, see Mann et al., Thinking Effects, 2.

16. Saunders-Newton and Frank, "Effects-Based Operations."

17. Interview with Air Command and Staff College faculty subjectmatter expert on targeting, 14 March 2005.

18. JP 5-0, Doctrine for Planning Joint Operations, III-3.

19. JP 3-30, Command and Control for Joint Air Operations, III-4.

20. Ibid., III- 10 .

21. AFDD 2, 70.

22. JP 3-30, III- 11 .

23. AFDD 2, 74 .

24. JP 3-60, III-2.

25. College of Aerospace Doctrine, Research and Education (CADRE) Joint Air Operations Planning Course, Joint Air Estimate Planning Handbook, version 2 (Maxwell AFB, Ala.: CADRE, 6 October 2003), 46.

26. Mann et al., 55. 
27. "Troops Put Thorny Questions to Rumsfeld," CNN, 9 December 2004, n.p., http://www.cnn.com/2004/WORLD/meast/12/08/rumsfeld. troops/.

28. Maj K. Noedskov, 2.

29. Air Force Instruction (AFI) 10-201, Status of Resources and Training System, 8 January 2002, 8.

30. Ibid., 8.

31. Ibid., 11.

32. Ibid., 181.

33. Ibid., 8.

34. Maj Luke Henry, 5.

35. Ibid., 5-7.

36. Ibid., 7 .

37. Ibid., 9.

38. Ibid., 10.

39. HQ ACC/DOTO FY 05 RAP tasking message to ACC F-16 Block 50 Operations Group commanders, memorandum, n.d. Reference includes a survey of ANG F-16, A-10, F-15C/E, and F-16 Block 30/40 RAP tasking messages.

40. Ibid., 3. Commander option sorties actually are a larger apportionment, but these sorties are for the expressed purpose of ensuring basicmission-capable pilots remain current and support the squadron mission. They can only be used on combat-mission-ready pilots in the squadron's DOC-tasked missions.

41. Ibid., 3-4.

42. These include those listed with direct combat applications. There are non-RAP requirements that are related to basic aircrew proficiency, such as trail departure and instrument penetrations.

43. Henry, Primer for RAP, 10.

44. ACC F-16 Block 50 Operations Group commanders, memorandum, note 7,5 .

45. See also Jack F. Harmon, "Building the Fighter Pilot."

46. Riza, "A Grand Unified Theory of Fighter Guantum Mechanics," $42-49$.

47. HQ ACC/DOTO, Air Force Research Lab, the Group for Organizational Effectiveness, Inc., and Aptima, Inc., are the joint owners of the service mark mission essential competencies. Terminology used here comes with permission of $\mathrm{HQ}$ ACC/DOTO, Chuck Colgrove.

48. HQ ACC/DOTO FY05 RAP tasking message to ACC F-15C Operations Group commanders, memorandum, n.d.; and interview with Chuck Colgrove, HQ ACC/DOTO.

49. Colgrove and Bennett, SEAD Mission Essential Competencies ${ }^{S M}, 3$.

50. Colgrove and Bennett, Air-to-Air Mission Essential Competencies ${ }^{\mathrm{SM}}$, 3.

51. Henry, Primer for RAP, 5.

52. JP 1-02, Department of Defense Dictionary of Military and Associated Terms, 522 .

53. Ibid.

54. Ibid., 389.

55. Ibid. 
56. Ibid., 507.

57. Ibid.

58. Gen Richard B. Meyers, former chairman of the Joint Chiefs of Staff, interview by George Stephanopoulos.

59. Twenty-first STUS/CC, "First 50 Orientations," briefing.

60. Joint Air Exercise facilitator.

61. USJFCOM Pamphlet 7, 2.

62. Deptula, Effects-Based Operations, 11.

63. During Operations Enduring Freedom and Iraqi Freedom, the USAF

Weapons School provided several augmentees to the United States Central Command (USCENTAF) CAOC at the request of the CENTAF/CC.

64. Hallion, Storm over Iraq, 199.

65. Murray and Major General Scales, The Iraq War, 155.

66. Henry, Primer for RAP, 9. 


\section{Bibliography}

Air Force Doctrine Document (AFDD) 1. Air Force Basic Doctrine, 17 November 2003.

AFDD 1-2. Air Force Glossary, 24 August 2004.

AFDD 2, Draft. "Organization and Employment for Air and Space Operations,” 10 May 2004.

Air Force Instruction (AFI) 10-201. Status of Resources and Training System, 8 January 2002.

Air Force Operational Tactics, Techniques, and Procedures (AFOTTP) 2-3.1. USAF Command and Control Nodes, 30 December 2004.

Colgrove, Chuck, and Dr. Winston Bennett, Jr. Air-to-Air Mission Essential Competencies. Headquarters (HQ) Air Combat Command (ACC)/Flight Operations and Training Branch (DOTO) and Air Force Research Laboratory (AFRL)/HEAS joint report. Langley AFB, Va.: HQ ACC/ DOTO, n.d.

- SEAD Mission Essential Competencies ${ }^{\mathrm{SM}}$. HQ ACC/ DOTO and AFRL/HEAS joint report. Langley AFB, Va.: HQ ACC/DOTO, n.d.

Deptula, Brig Gen David A., USAF. Effects-Based Operations: Change in the Nature of Warfare. Report for the Aerospace Education Foundation, Defense and Air Power Series. Arlington, Va.: Aerospace Education Foundation, 2001.

Gleeson, Dennis J., Col Gwen Linde, Kathleen McGrath, Adrienne J. Murphy, Williamson Murray, Tom O'Leary, and Joel B. Resnick. New Perspectives on Effects-Based Operations: Annotated Briefing. Institute for Defense Analyses, Joint Advanced Warfighting Program, Document D-2583. Alexandria, Va.: Institute for Defense Analyses, 2001.

Hallion, Richard P. Storm over Iraq: Air Power and the Gulf War. Washington, D.C.: Smithsonian Institution Press, 1992.

Harmon, Capt Jack F., USAF. "Building the Fighter Pilot: Developing Transferable Skill Sets." USAF Weapons 
School student paper, June 2004. https://wwwmil.nellis. af.mil/usafws/f16sp.htm.

Hayes, Richard E., Susan Iwanski, and Corrina RossWitkowski, eds. Analyzing Effects-Based Operations Report. Workshop Proceedings. Alexandria, Va.: Military Operations Research Society, January 2003.

Henry, Maj Luke, USAF. A Primer for Ready Aircrew Program (RAP). Air Combat Command (ACC) report. Langley AFB, Va.: ACC/DOTO, n.d.

HQ ACC/DOT FY 05 RAP tasking message. To ACC F-15C Operations Group Commanders. Memorandum, n.d.

HQ ACC/DOT FY 05 RAP tasking message. To F-16 Block 50 Operations Group Commanders. Memorandum, n.d.

Joint Air Estimate Planning Handbook, Version 2. College of Aerospace Doctrine, Research and Education (CADRE) Joint Air Operations Planning Course. Maxwell AFB, Ala.: CADRE, 6 October 2003.

Joint Air Exercise Facilitator. Air Command and Staff College, 31 March 2005.

Joint Publication (JP) 1-02. Department of Defense Dictionary of Military and Associated Terms, 12 April 2001 (as amended through 31 August 2005).

JP 3-09.3. Joint Tactics, Techniques, and Procedures for Close Air Support, 3 September 2003.

JP 3-30. Command and Control for Joint Air Operations, 5 June 2003.

JP 3-60. Joint Doctrine for Targeting, 17 January 2002.

JP 5-0. Doctrine for Planning Joint Operations, 13 April 1995.

Mann, Edward C., III, Gary Endersby, and Thomas R. Searle. Thinking Effects: Effects-Based Methodology for Joint Operations. CADRE Paper 15. Maxwell AFB, Ala.: Air University Press, October 2002.

Murray, Williamson, and Maj Gen Robert H. Scales, Jr., US Army, retired. The Iraq War, A Military History. Cambridge, Mass.: The Belknap Press of Harvard University Press, 2003.

Noedskov, Maj K., Royal Danish Air Force. "SystemizingEffects Based Air Operations." Air and Space Power 
Chronicles. Maxwell AFB, Ala.: Air University Press, May 2000.

Riza, Maj M. Shane, USAF. "A Grand Unified Theory of Fighter Quantum Mechanics: The Rationale for Airto-Air Training in Multi-role Fighters." USAF Weapons Review 51, issue 4 (Winter 2003): 42-49.

Saunders-Newton, Desmond, and Aaron B. Frank. "EffectsBased Operations: Building the Analytic Tools." Defense Horizons, no. 19. Washington, D.C.: National Defense University, October 2002.

“Troops Put Thorny Questions to Rumsfeld." CNN, 9 December 2004. n.p. http://www.cnn.com/2004/WORLD/meast/ 12/08/rumsfeld.troops/.

Twenty-first STUS/CC, "First 50 Orientations." Briefing. Maxwell AFB, Ala.: Air Command and Staff College, 20 July 2004.

United States Joint Forces Command (USJFCOM). Joint Warfighting Center Joint Doctrine Series Pamphlet 7, Operational Implications of Effects-Based Operations (EBO), 17 November 2004. 


\section{Appendix A}

\section{Strategy to Task Linkage}

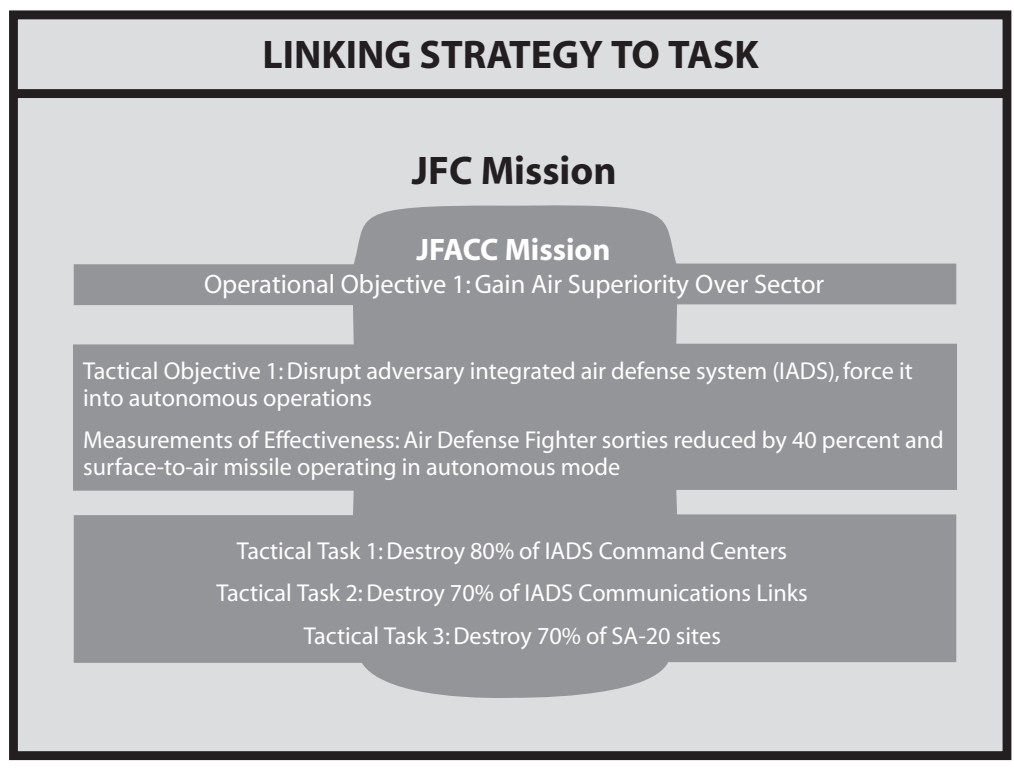

(Reprinted from JP 3-30, Command and Control for Joint Air Operations, fig. III-6). 


\section{Appendix B}

\section{Sample DOC Statement from AFI 10-201}

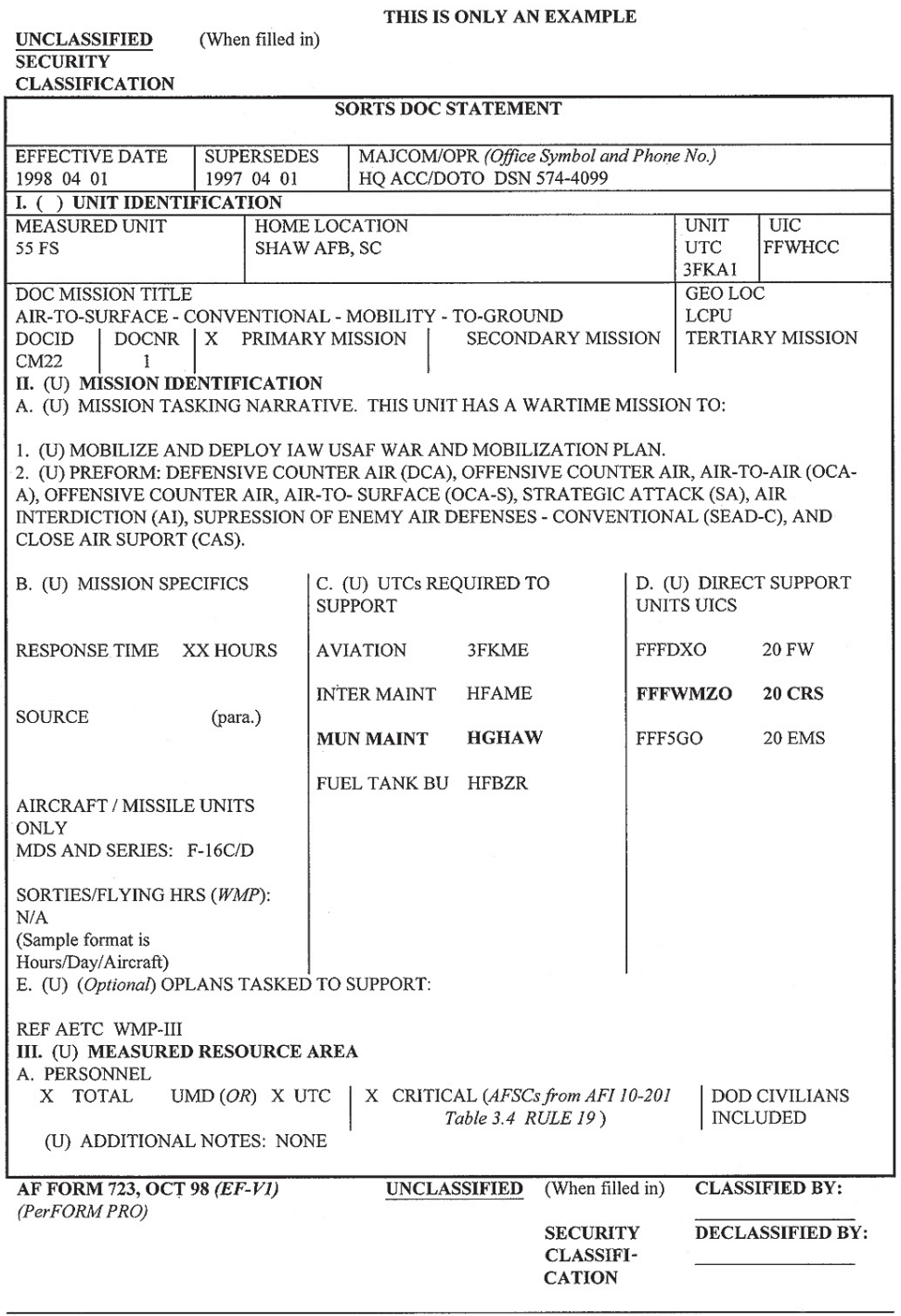




\title{
Appendix B (Continued)
}

\author{
THIS IS ONLY AN EXAMPLE \\ UNCLASSIFIED (When filled in) \\ SECURITY
}

CLASSIFICATION

III. (U) MEASURED RESOURCE AREA (Continued)

D. (U) TRAINING

METHOD B : $\square$ CREW

TRAINING

METHOD C: OPTION $1 \square$ UNIT TRAINING $\square$ OPTION 2 X COMBAT AIR FORCES

(U) ADDITIONAL NOTES:

AVIATION TRAINING

C-LEVELS WILL BE DETERMINED IAW AFI 10-201, TABLE 6.3, METHOD C, OPTION 2. MISSIONS LISTED IN SECTION II ARE THE BASIS FOR THE TRAINING MEASURED AREA C-LEVEL. TO MEET MISSION REQUIREMENTS, SOME PILOTS REQUIRE ADDITIONAL QUALIFICATIONS/ TRAINING TO BE COUNTED MRA.

(In this sample, the unit is tasked to report training of Combat Air Forces and Support Units.)

IV. (U) AMPLIFYING NOTES (As required):

A. (U) MISSION CAPABILITIES LISTED IN SECTION II ARE MEASURED IN THE OVERALL C-LEVEL. ADDITIONALLY, SPECIAL CAPABILITIES, WHICH REQUIRE LESS THAN ALL AIRCREWS TO BE TRAINED, WILL BE REPORTED IAW AFI 10-201.

B. (U) UTCS WILL BE TAILORED UNTIL SEPARATE 18 PMAI BK 50 DEP GP UTCS ARE DEVELOPED FOR THE 55 FS.

C. (U) NO ADDITIONAL EQUIPMENT IS AUTHORIZED FOR HTS TRAINING. SQUADRON WILL UTILIZE EXISTING ASSETS TO TRAIN PILOTS IN THE USE OF HTS.

$* * *($ CONTINUED SECTION III B. $) * * *$

USE WSMIS DERIVED PERCENTAGES FOR SPARE ASSESSMENT (SORTIE GENERATION, DRIVER CODE Y UNDER LABEL ARUSD) UNLESS WSMIS IS NOT AVAILABLE, OR INACCURATE, THEN USE DMAS (ALSO DRIVER CODE $Y$ ). IF DMAS IS NOT AVAILABLE, USE FILL RATES (DRIVER CODE $X$ UNDER THE LABEL ARUSD). IF WSMIS IS AVAILABLE AND ACCURATE BUT ASSESSES LESS THAN C-1, REPORT WSMIS RATE IN LABEL ARUSD THEN USE DMAS AS A COMMANDER'S ASSESSMENT TOOL TO SUBJECTIVELY ASSESS THE UNIT'S OVERALL C-LEVEL (IF APPROPRIATE) AND THEN REPORT THE DMAS SORTIE PERCENTAGE AND DMAS PROBLEM PARTS IN THE ESSA1 REMARK.

\begin{tabular}{|c|c|c|}
\hline $\begin{array}{l}\text { AF FORM 723, OCT } 98(\mathbf{E F}-\boldsymbol{V} \mathbf{1}) \\
(P e r F O R M P R O)\end{array}$ & UNCLASSIFIED & (When filled in) \\
\hline & $\begin{array}{l}\text { SECURITY } \\
\text { CLASSIFICATION }\end{array}$ & \\
\hline
\end{tabular}




\section{Appendix C}

\section{Levels of War Definitions}

(Reprinted from JP 1-02, Department of Defense Dictionary of Military and Associated Terms, 12 April 2001, as amended through 31 August 2005)

strategic level of war-The level of war at which a nation, often as a member of a group of nations, determines national or multinational (alliance or coalition) security objectives and guidance, and develops and uses national resources to accomplish these objectives. Activities at this level establish national and multinational military objectives; sequence initiatives; define limits and assess risks for the use of military and other instruments of national power; develop global plans or theater war plans to achieve these objectives; and provide military forces and other capabilities in accordance with strategic plans.

operational level of war-The level of war at which campaigns and major operations are planned, conducted, and sustained to accomplish strategic objectives within theaters or other operational areas. Activities at this level link tactics and strategy by establishing operational objectives needed to accomplish the strategic objectives, sequencing events to achieve the operational objectives, initiating actions, and applying resources to bring about and sustain these events. These activities imply a broader dimension of time or space than do tactics; they ensure the logistic and administrative support of tactical forces, and provide the means by which tactical successes are exploited to achieve strategic objectives.

tactical level of war-The level of war at which battles and engagements are planned and executed to accomplish military objectives assigned to tactical units or task forces. Activities at this level focus on the ordered arrangement and maneuver of combat elements in relation to each other and to the enemy to achieve combat objectives. 


\section{Appendix D}

\section{Modules of National Policy Concept}

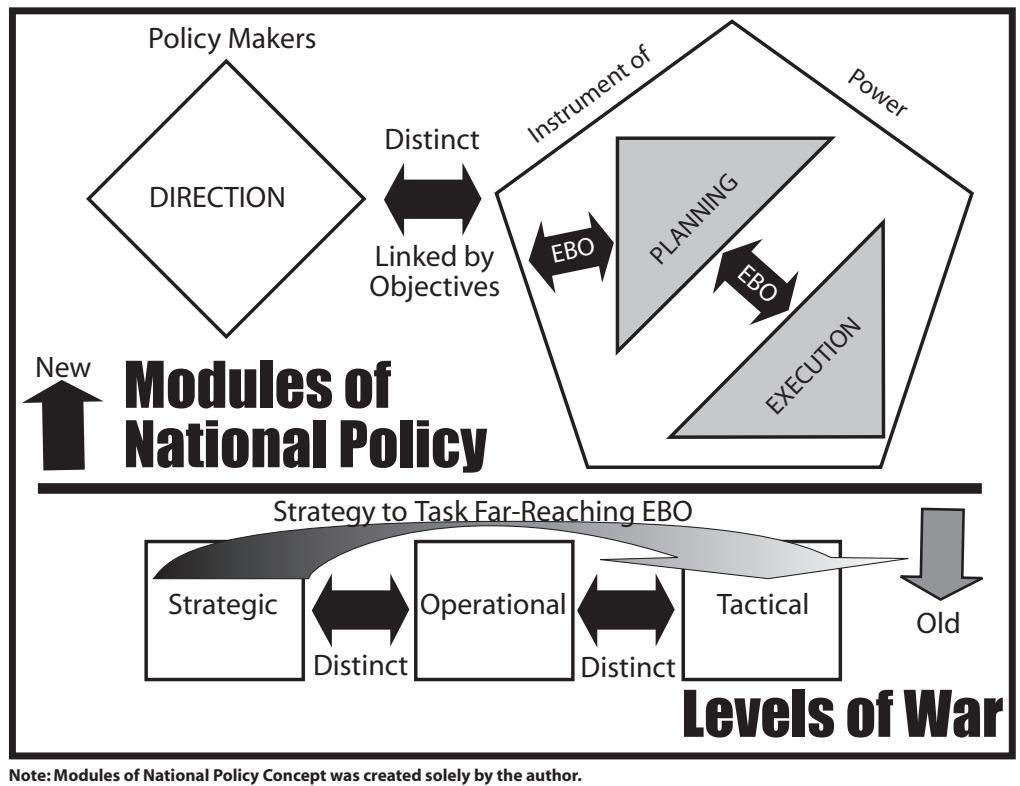

